\title{
Effects of horizontal web reinforcement on cyclic behavior of RC squat walls
}

\author{
Leonardus S.B. Wibowo ${ }^{1, *}$, and Min-Yuan Cheng $^{2}$ \\ ${ }^{1}$ Universitas Widya Kartika, Civil Engineering Department, Surabaya, Indonesia \\ ${ }^{2}$ National Taiwan University of Science and Technology, Civil and Construction Engineering Department, Taipei, Taiwan
}

\begin{abstract}
This paper evaluates the effects of horizontal web reinforcement on cyclic behaviour of RC squat wall using test results of three pairs of specimens. One specimen was tested by the authors while the other five were adopted from the existing researches. Each specimen pair was designed with approximately the same design parameters, except that uniformly distributed horizontal web reinforcement was provided in one specimen only. Shear stress demand, evaluated based on the shear associated with the development of flexural strength at the base, was approximately $3.5 \sqrt{f_{c}^{\prime}}(\mathrm{psi}), 6.0 \sqrt{f_{c}^{\prime}}(\mathrm{psi})$, and $8.0 \sqrt{f_{c}^{\prime}}$ (psi), respectively, for each specimen pair. Test results show that specimen with uniformly distributed horizontal web reinforcement exhibited larger deformation capacity compared to specimens without it. Specimen peak strengths, on the other hand, appear to be similar with and without uniformly distributed horizontal reinforcement and can be satisfactorily predicted by nominal flexural strength.
\end{abstract}

\section{Introduction}

Reinforced concrete (RC) shear wall not only provides lateral strength but also keeps lateral deformation within acceptable limits due to its large in-plane stiffness. According to Moehle et al. [1], RC shear walls are often more cost-effective than RC moment-resisting frames for low-to-medium-rise structures. A RC squat wall typically refers to a structural wall having an aspect ratio $\left(h_{w} / \ell_{w}\right)$ of 2.0 or less, where $h_{w}$ is the wall height, measured from center of the load application to the base of the wall and $\ell_{w}$ is the wall length.

Researches on effects of horizontal reinforcement on load-deformation responses of RC squat walls have been conducted previously [2,3]. Maier [2] tested a total of 10 squat wall specimens with $h_{w} / \ell_{w}$ of around 1.10. Two specimens, specimens $\mathrm{S} 4$ and $\mathrm{S} 9$, were designed identically except that no horizontal reinforcement was provided in specimen S9. Under approximately $0.08 A_{g} f_{c}$, axial force and monotonically increased lateral displacement, test results showed that two specimens exhibited similar peak lateral strength but slightly different deformation capacity. Specimen S4 achieved larger deformation capacity of $1.11 \%$ compared to $0.93 \%$ from specimen S9. Similar findings were reported by Greifenhagen and Lestuzzi [3] from results of specimens M1 and M2 with $h_{w} / \ell_{w}$ of around 0.70 as well. Specimens
M1 and M2 were subjected to combined axial force of approximately $0.03 A_{g} f_{c}^{\prime}$ and cyclic lateral loading.

Please note, Maier[2] and Greifenhagen and Lestuzzi [3] tested the specimens with peak lateral strength around $6.8 A_{c v} \sqrt{f_{c}}(\mathrm{psi})$ and $3.5 A_{c v} \sqrt{\dot{f}}(\mathrm{psi})$, respectively, where $A_{c v}$ is the wall cross section. A recent publication (Cheng et al. [4]) indicates that deformation capacity of RC squat walls subjected to lateral displacement reversals decreases as the normalized peak shear stress, i.e, peak lateral strength divided by $A_{c v} \sqrt{f_{c}}$, increases. It is then of interest whether the previous findings are applicable to walls with high shear stress demand, for example, with shear stress demand close to $10 A_{c v} \sqrt{f_{c}}(\mathrm{psi})$, a stress limit currently set by ACI 318-14[5]. This study aims to extend the experimental work of the aforementioned researches and systematically investigate the effects of uniformly distributed horizontal web reinforcement on cyclic behavior of RC squat wall with high shear stress demand. With two pair of specimens collected from Maier [2] and Greifenhagen and Lestuzzi [3], one specimen, H60_V, was designed identically with specimen $\mathrm{H} 60$ tested by

\footnotetext{
* Corresponding author: bowobudi84@gmail.com
} 
Cheng et al. [4], except that no horizontal reinforcement is provided.

A test matrix that illustrates the key test parameters in specimens H60 and H60_V is summarized in Table 1. Unfortunately, design parameters in specimens S4, S9, M1, and M2 are not available because specified material strength was not reported, and thus only test results of those specimens are presented. In Table $1, V_{m n}$ and $V_{m p r}$ is the shear assocated with the development of nominal flexural strength, $M_{n}$, and probable flexural strength, $M_{p r}$, at the wall base, respectively. That is, $V_{m n}=M_{n} / h_{w}$ and $V_{m p r}$ $=M_{p r} / h_{w}$, where $M_{p r}$ is determined using 1.25 steel specified yield strength. As can be seen from $v_{m p r} / \sqrt{f_{c}}$, specimen $\mathrm{H} 60$ and H60_V were designed with shear stress demand close to $10 A_{c v} \sqrt{f_{c}^{\prime}}$ (psi).

$V_{n 1}$ and $V_{n 2}$ is the nominal shear capacity determined based on Eq. 1, and Eq. 2, respectively, per ACI 318-14 [5], $A_{c v}$ is the wall cross section area determined by wall width $\left(b_{w}\right)$ times the wall length $\left(\ell_{w}\right)$, and $\rho_{t}$ is the horizontal web reinforcement ratio.

$$
\begin{gathered}
V_{n 1}=A_{c v}\left(3 \sqrt{f_{c}}+\rho_{t} f_{y}\right) \leq 10 \sqrt{f_{c}^{\prime}} A_{c v}, \mathrm{psi} \\
V_{n 2}=0.6 A_{v f} f_{y} \leq \min \left(0.2 \dot{f}_{c}^{\prime} A_{c v},\right. \\
\left.\left(480+0.08 \dot{f}_{c}^{\prime}\right) A_{c v}, 1600 A_{c v}\right), \mathrm{psi}
\end{gathered}
$$

In addition to the code design equations, another three shear strength prediction models are also used to evaluate specimen peak strength later. Equation (3), which has a form similar to Eq. (2), was proposed by Wood [6] based on a database consisting of $143 \mathrm{RC}$ squat wall specimens. In which, $A_{v f}$ is the area of total vertical reinforcement in the wall (sum of areas of vertical web reinforcement and longitudinal reinforcement in the special boundary element).

$$
6 \sqrt{\dot{f}_{c}} A_{c v} \leq V_{n 3}=0.25 A_{v f} f_{y} \leq 10 \sqrt{f_{c}^{\prime}} A_{c v}, \mathrm{psi}
$$

Another model, known as simplified softened strut-andtie (SSST) model by Hwang and Lee [7], was developed assuming that shear resisted by the wall is transferred through three mechanisms including diagonal struts, horizontal ties, and vertical ties. The shear strength $\left(V_{n 4}\right)$ per SSST model can be determined using Eq. (4), where $K_{h}$ and $K_{v}$ is the reinforcement index for horizontal and vertical reinforcement, respectively. $\zeta$ is the concrete softening coefficient, $A_{s t r}$ is the diagonal strut area and $\theta$ is the angle of inclination.

$$
V_{n 4}=\left(K_{h}+K_{v}-1\right) \zeta f_{c}^{\prime} A_{s t r} \cos \theta
$$

Gulec and Whittaker [8] used an extensive database consisting of 148 specimens and proposed an empirical shear strength prediction model as shown in Eq. (5). This empirical relation was proposed to evaluate the mean shear resistance of the rectangular RC squat walls with aspect ratios of 1.0 or less.

$$
\begin{gathered}
V_{n 5}=\frac{1.5 \sqrt{f_{c}^{\prime}} A_{c v}+0.25 F_{v w}+0.2 F_{v b e}+0.4 N}{\sqrt{h_{w} / \ell_{w}}} \leq \\
10 \sqrt{f_{c}^{\prime}} A_{c v}, \text { psi }
\end{gathered}
$$

where $A_{c v}$ is the wall area that can be determined as the product of wall thickness $\left(t_{w}\right)$ and wall length $\left(\ell_{w}\right), f_{c}$ is

\begin{tabular}{|c|c|c|c|c|}
\hline Specimen & $\begin{array}{c}v_{m n} / \sqrt{f_{c}^{\prime}}(\mathbf{1 )}, \\
\text { psi } \\
(\mathbf{M P a})\end{array}$ & $\begin{array}{c}v_{m p r} / \sqrt{f_{c}^{\prime}}(2) \\
\text { psi } \\
(\mathbf{M P a})\end{array}$ & $\begin{array}{c}v_{n 1} / \sqrt{f_{c}^{\prime}}{ }^{(3)}, \\
\mathbf{p s i} \\
(\mathbf{M P a})\end{array}$ & $\begin{array}{c}v_{n 2} / \sqrt{f_{c}^{\prime}}{ }^{(4)}, \\
\text { psi } \\
\text { (MPa) }\end{array}$ \\
\hline H60 [4] & $\begin{array}{c}7.87 \\
(0.66)\end{array}$ & $\begin{array}{c}9.68 \\
(0.81)\end{array}$ & $\begin{array}{c}9.44 \\
(0.79)\end{array}$ & $\begin{array}{l}10.93 \\
(0.91)\end{array}$ \\
\hline H60_V & $\begin{array}{c}7.87 \\
(0.66)\end{array}$ & $\begin{array}{c}9.68 \\
(0.81)\end{array}$ & $\begin{array}{c}3.00 \\
(0.25)\end{array}$ & $\begin{array}{l}10.93 \\
(0.91)\end{array}$ \\
\hline
\end{tabular}
the concrete compressive strength of concrete, $F_{v w}$ is the force attributed to vertical web reinforcement, $F_{v b e}$ is the force attributed to boundary element reinforcement, $N$ is the axial force applied to the wall, $h_{w}$ is the wall height, and $\ell_{w}$ is the wall length.

Table 1. Test Parameters Using Specified Material Strength

\section{Experimental Program}

\subsection{Test Specimen}

Reinforcement layouts of the 6 specimens are presented in Fig. 1. Please note, specimen H60_V, S9, and M2 was designed to have all design parameters identical to specimen H60, S4, and M1, respectively, except that no horizontal reinforcement is provided.

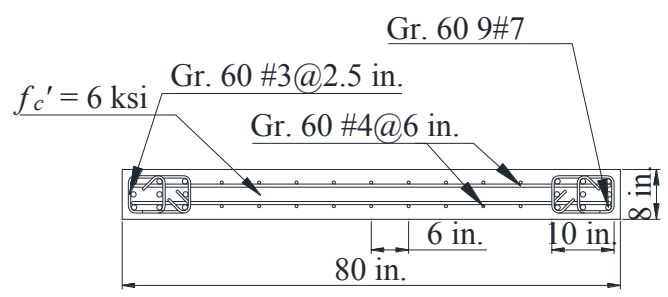

(a) $\mathrm{H} 60$ [4]

Gr. $609 \# 7$

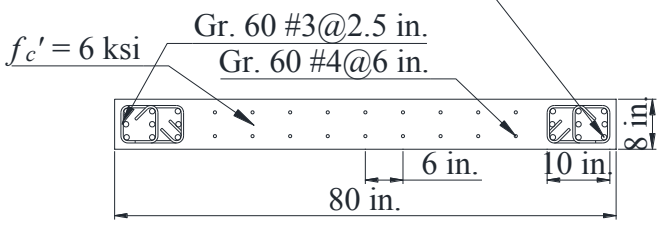

(b) H60_V 


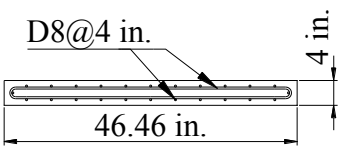

(c) S4 [2]

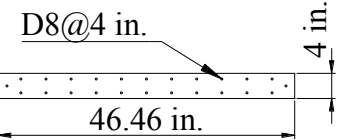

(d) S9 [2]

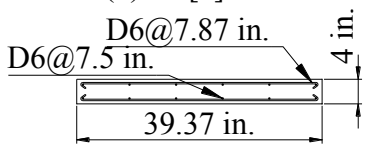

(e) M1 [3]

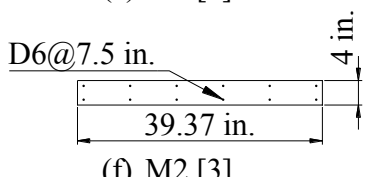

Fig. 1. Nominal dimensions and reinforcement layout for test specimens $(1$ in. $=25.4 \mathrm{~mm})$

\subsection{Experimental Setup and Instrumentation}

The experimental setup for both specimen H60 and H60_V is shown in Fig. 2. This setup intends to impose in-plane single-curvature deformation to the test specimens with negligible axial force. Due to length limitation, experimental layouts for the other 4 specimens can be found elsewhere $[2,3]$.

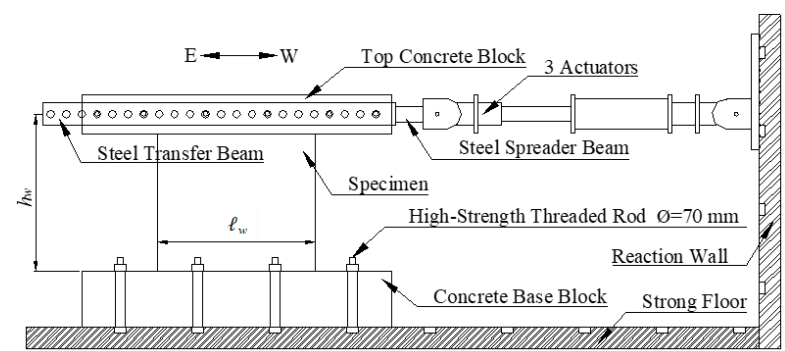

Fig. 2. Test Setup

\section{Experimental Results}

\subsection{Overall Response}

Based on test result from Cheng et al. [4], specimen H60 exhibited extensive deterioration along the base of the wall at the final state, as can be seen in Fig. 3(a). For specimen H60_V, inclined and horizontal cracks developed in test specimens during the $1^{\text {st }}$ cycle at $0.25 \%$ target drift level. More cracks developed as the target drift increased from $0.25 \%$ to $0.75 \%$. As the specimen was pushed to the target drift of $1.00 \%$, widths of some inclined cracks grew wider and spall-off of concrete cover was observed at center of the wall where the two major inclined cracks intersected. Before reaching the target drift of $1.00 \%$, a major inclined crack propagated from upper left corner to the lower right corner suddenly opened and lateral resistance started to drop after that. As the specimen was loaded to $1.50 \%$ target drift, the major inclined crack widths grew even wider and the lateral resistance dropped more than $50 \%$ from the peak in both loading directions at peaks of the $1^{\text {st }}$ cycle of $1.50 \%$ target drift. Test terminated after completion of the $1.50 \%$ target drift cycles. Final state of the test specimen is presented in Fig. 3(b).

For specimen S4, based on visual observation of Fig. 3(c), in addition to have several inclined cracks at bottom half of the wall, several damage including spall-off of the concrete cover and buckling of the vertical reinforcement appears to localize at lower corner of the wall. Final state of specimen S9 shows similar failure mode but with a few inclined cracks that opened more widely.

Specimen M1 and M2 [4] show similar failure mode as well, Fig. 3(e) and 3(f). Cracks and concrete spall-off were primarily observed along the wall base and within a narrow height. The outmost vertical reinforcement ruptured as specimen M1 was loaded to $3.00 \%$, while the outmost vertical reinforcement in specimen M2 buckled at the end of the test. According to the authors, sliding movement of the two specimens contributed substantially to the top lateral displacement in the last few drift cycles.

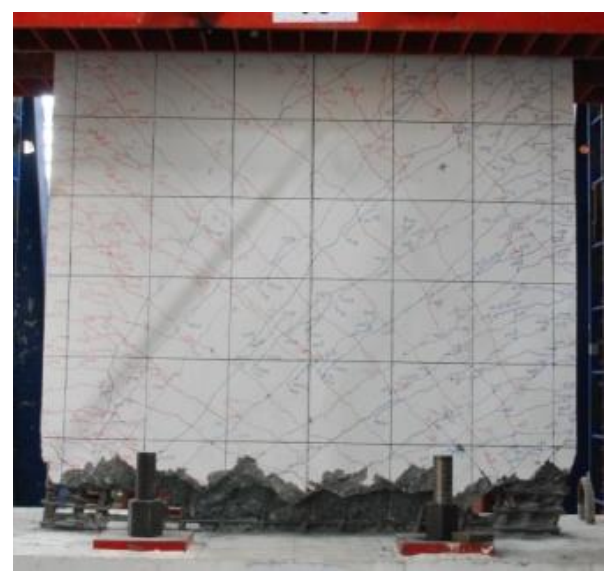

(a) $\mathrm{H} 60[4]$

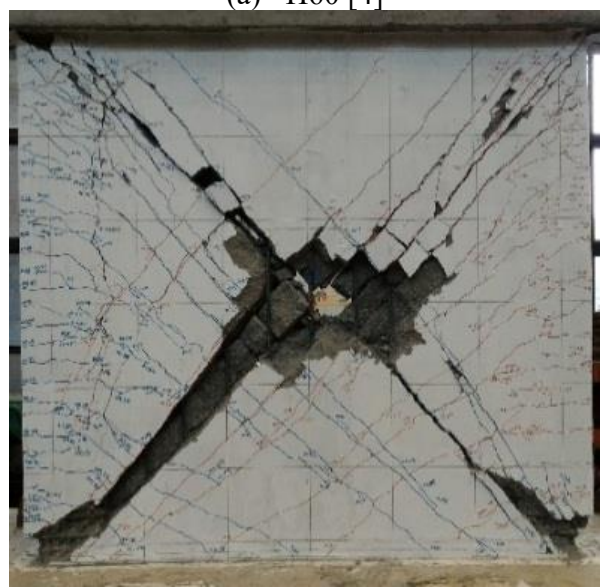

(b) H60_V 


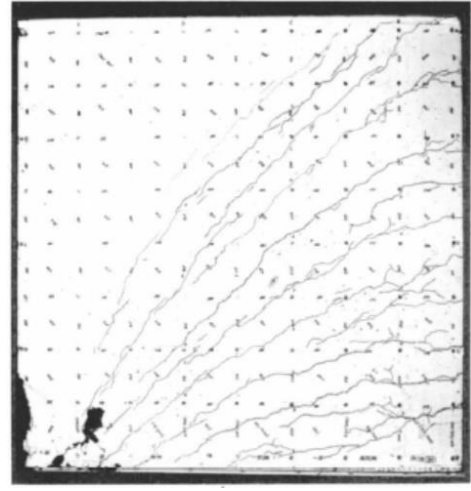

(c) S4 [2]

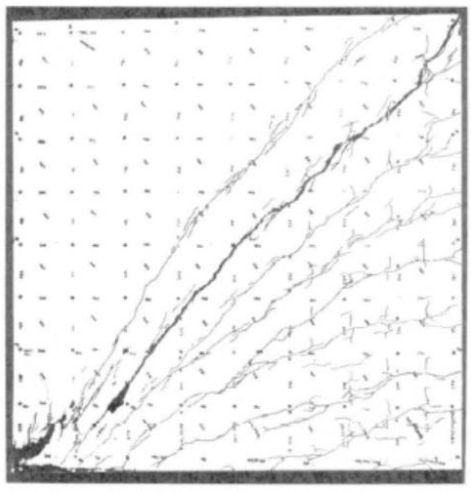

(d) S9 [2]

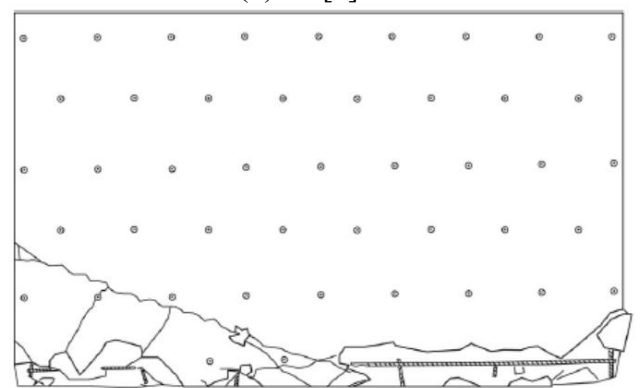

(e) M1 [3]

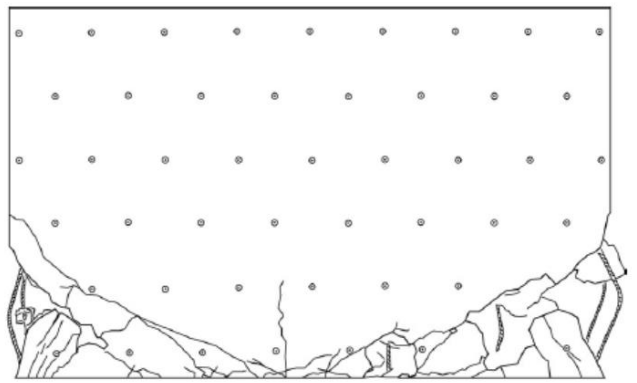

(f) M2 [3]

Fig. 3. Final States of Test Specimens

\subsection{Test Results}

Concrete cylinder strength was $6.4,6.7,4.8,4.2,7.3$ and $7.4 \mathrm{ksi}(44,46,33,29,50$, and $51 \mathrm{MPa})$ for specimen H60 [4], H60_V, S4 [2], S9 [2], M1 [3] and M2 [3] respectively. Steel coupon test results are listed in Table 3. Load-deformation responses of the six specimens are presented in Fig. 4. As shown in Fig. 4, the peak strength of specimens reinforced with/without horizontal web reinforcement were similar but there were differences in the deformation of the specimens. Specimens with horizontal web reinforcement had greater deformation than specimens without horizontal web reinforcement. Some key test results of the six specimens are summarized in Table 4. Ultimate drift ratio $d_{u}$ is defined at the point when one of the following two criteria is first met: 1) the drift where the load drops $20 \%$ from the peak on the envelope curve; or 2) the drift where the load drops more than $20 \%$ in the repeated cycles and the load in the $1^{\text {st }}$ cycle of the next drift level is lower than the load in the $3^{\text {rd }}$ cycle of this drift level. The loading direction in which $d_{u}$ is determined is consistent with that of $V_{\text {peak }}$, the larger peak strengths from the two loading directions.

Table 3 - Summary of Reinforcement Properties

\begin{tabular}{|c|c|c|c|c|c|c|}
\hline $\begin{array}{c}\text { Specimen } \\
\text { name }\end{array}$ & \multicolumn{2}{|c|}{$\begin{array}{c}\text { Vertical } \\
\text { Reinf. in } \\
\text { SBE*, ksi } \\
\text { (MPa) }\end{array}$} & \multicolumn{2}{|c|}{$\begin{array}{c}\text { Web } \\
\text { Reinf., ksi } \\
\text { (MPa) }\end{array}$} & \multicolumn{2}{c|}{$\begin{array}{c}\text { Confinement } \\
\text { Reinf., ksi } \\
\text { (MPa) }\end{array}$} \\
\hline H60 [4] & $\# 7$ & $\begin{array}{c}65 \\
(448)\end{array}$ & $\# 4$ & $\begin{array}{c}69 \\
(473)\end{array}$ & $\# 3$ & $\begin{array}{c}66 \\
(453)\end{array}$ \\
\hline H60_V & $\# 7$ & $\begin{array}{c}65 \\
(448)\end{array}$ & $\# 4$ & $\begin{array}{c}69 \\
(473)\end{array}$ & $\# 3$ & $\begin{array}{c}65 \\
(451)\end{array}$ \\
\hline S4 [2] & - & - & D8 & $\begin{array}{c}83 \\
(574)\end{array}$ & - & - \\
\hline S9 [2] & - & - & D8 & $\begin{array}{c}83 \\
(574)\end{array}$ & - & - \\
\hline M1 [3] & - & - & D6 & $\begin{array}{c}73 \\
(504)\end{array}$ & - & - \\
\hline M2 [3] & - & - & D6 & $\begin{array}{c}73 \\
(504)\end{array}$ & - & - \\
\hline
\end{tabular}

*SBE: special boundary element.

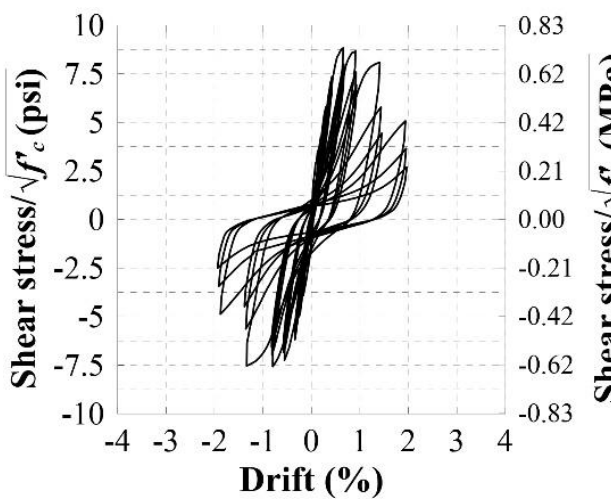

(a) $\mathrm{H} 60[4]$

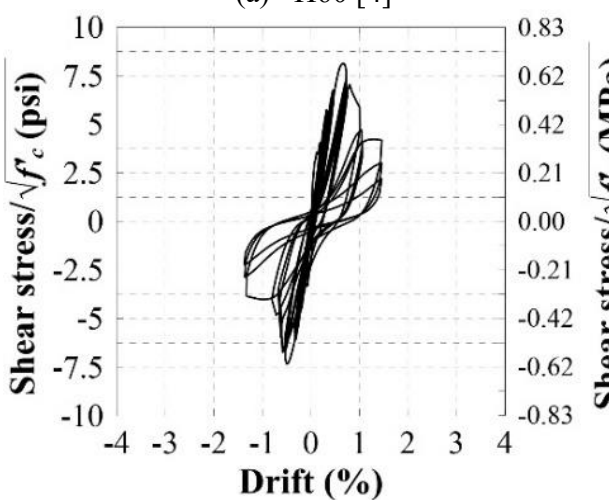

(b) H60_V 


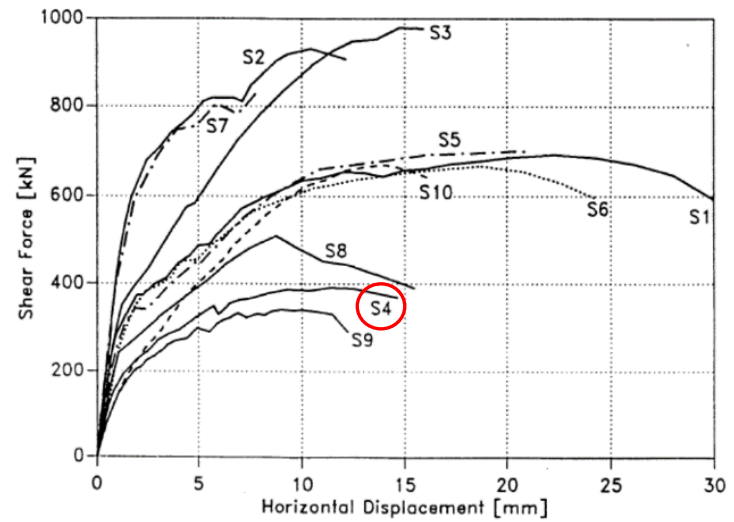

(c) S4 [2]

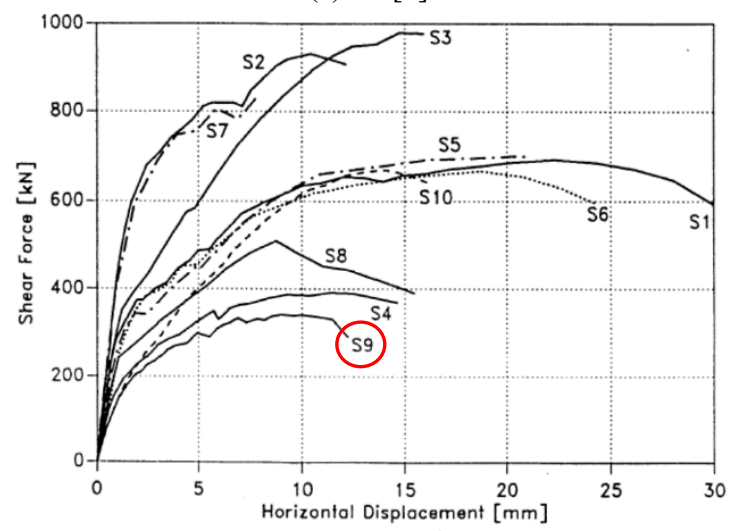

(d) S9 [2]

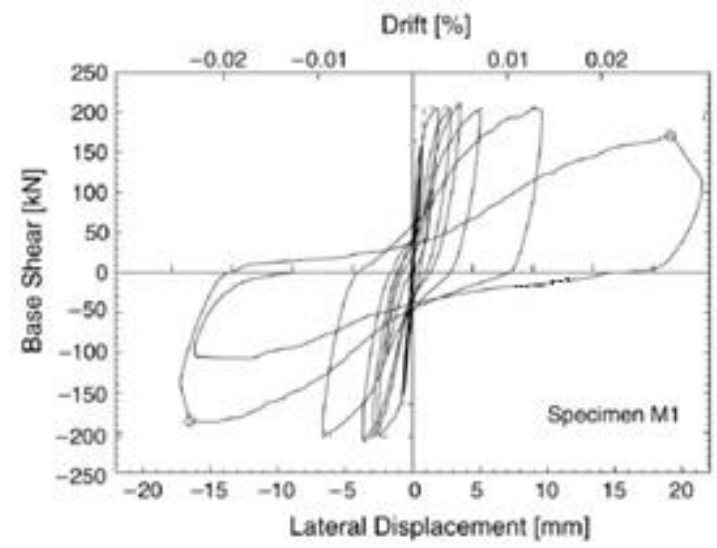

(e) M1 [3]

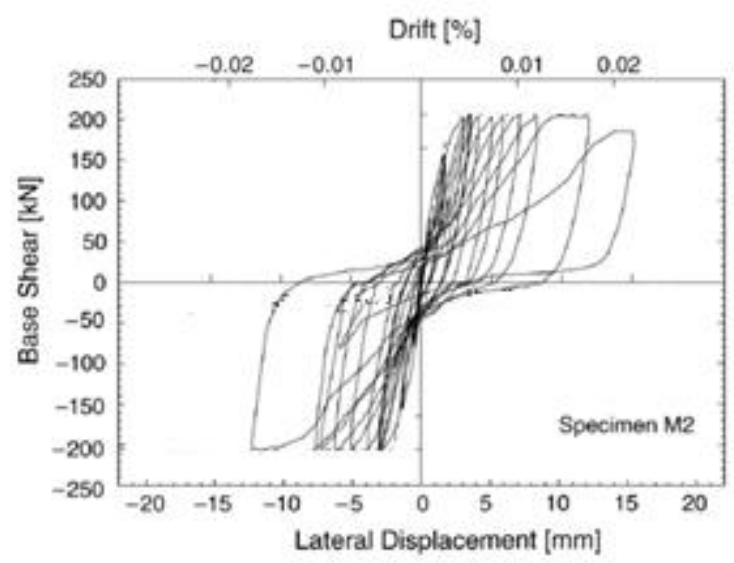

(f) M2 [3]

Fig. 4. Load - deformation relationship
Table 4 - Summary of Test Result

\begin{tabular}{|c|c|c|c|c|}
\hline $\begin{array}{l}\text { Specimen } \\
\text { name }\end{array}$ & $\begin{array}{l}V_{\text {peak, }} \\
\text { kips } \\
(\mathbf{k N})\end{array}$ & $\begin{array}{c}\frac{V_{\text {peak }}}{A_{c v} \sqrt{f_{c}^{\prime}}}, \text { psi } \\
\text { (МРa) }\end{array}$ & $\begin{array}{l}d_{u}, \\
\%\end{array}$ & $\begin{array}{l}\text { Failure } \\
\text { Mode* }\end{array}$ \\
\hline H60 [4] & $\begin{array}{c}443 \\
(1969)\end{array}$ & $\begin{array}{c}8.88 \\
(0.74)\end{array}$ & 1.59 & $\begin{array}{c}\text { Flexure - } \\
\text { Sliding }\end{array}$ \\
\hline H60_V & $\begin{array}{c}413 \\
(1819)\end{array}$ & $\begin{array}{c}8.03 \\
(0.67)\end{array}$ & 0.86 & $\begin{array}{c}\text { Flexure - } \\
\text { Diagonal } \\
\text { Web }\end{array}$ \\
\hline $\mathrm{S} 4$ [2] & $\begin{array}{l}88.12 \\
(392)\end{array}$ & $\begin{array}{c}6.98 \\
(0.58)\end{array}$ & 1.11 & $\begin{array}{c}\text { Flexure - } \\
\text { Diagonal } \\
\text { Compression }\end{array}$ \\
\hline S9 [2] & $\begin{array}{l}76.89 \\
(342)\end{array}$ & $\begin{array}{c}6.46 \\
(0.54)\end{array}$ & 0.93 & $\begin{array}{c}\text { Flexure - } \\
\text { Diagonal } \\
\text { Web } \\
\end{array}$ \\
\hline M1 [3] & $\begin{array}{l}47.51 \\
(211)\end{array}$ & $\begin{array}{c}3.57 \\
(0.30)\end{array}$ & 2.78 & $\begin{array}{c}\text { Flexure - } \\
\text { Sliding }\end{array}$ \\
\hline M2 [3] & $\begin{array}{l}46.31 \\
(206) \\
\end{array}$ & $\begin{array}{c}3.47 \\
(0.29) \\
\end{array}$ & 1.73 & $\begin{array}{c}\text { Flexure - } \\
\text { Sliding } \\
\end{array}$ \\
\hline
\end{tabular}

\subsubsection{Strength}

As can be seen from Table 5, the $V_{\text {peak }} / V_{m n}$ ratios indicate that peak strengths of all test specimens appear to be satisfactorily estimated by $V_{m n}$, the shear demand associated with development of the nominal flexural strength $\left(M_{n}\right)$ at the wall base, i.e. $V_{m n}=M_{n} / h_{w}$. Despite of this, shear capacity, particularly for specimens without horizontally distributed web reinforcement, appears to be exhausted simultaneously as the specimen achieved its peak strength, as can be seen in the load - deformation relationship and observation during the test. As a result, specimen peak strength is further evaluated using the aforementioned shear strength models. It should be noted that $V_{n 1}$ and $V_{n 4}$ are associated with the web shear failure mode, while $V_{n 2}$ and $V_{n 3}$ are associated with the friction shear failure mode. The shear strength model proposed by Gulec and Whittaker [8], $V_{n 5}$, is derived using regression analysis without associating with any specific failure modes. Among $V_{n 1}, V_{n 4}$, and $V_{n 5}$, based on results shown in Table 5, it appears $V_{n 4}$ provides the closest estimation for specimens H60_V, S4 and S9 that appears to fail in web shear.

For specimens that appear to fail in sliding shear, specimens H60, M1 and M2, neither $V_{n 2}, V_{n 3}$, and $V_{n 5}$ are able to provide consistent estimation. However, $V_{n 3}$ provides the most conservative results.

Table 5 - Shear Strength Evaluation

\begin{tabular}{|c|c|c|c|c|c|c|}
\hline Name & $\frac{\boldsymbol{V}_{\text {peak }}}{\boldsymbol{V}_{\boldsymbol{m} \boldsymbol{n}}}$ & $\frac{\boldsymbol{V}_{\text {peak }}}{\boldsymbol{V}_{\boldsymbol{n} \mathbf{1}}}$ & $\frac{\boldsymbol{V}_{\text {peak }}}{\boldsymbol{V}_{\boldsymbol{n} \mathbf{2}}}$ & $\frac{\boldsymbol{V}_{\text {peak }}}{\boldsymbol{V}_{\boldsymbol{n} \mathbf{3}}}$ & $\frac{\boldsymbol{V}_{\text {peak }}}{\boldsymbol{V}_{\boldsymbol{n} \mathbf{4}}}$ & $\frac{\boldsymbol{V}_{\text {peak }}}{\boldsymbol{V}_{\boldsymbol{n} \mathbf{5}}}$ \\
\hline H60 [4] & 1.09 & 0.84 & 0.78 & 1.86 & 1.20 & 1.61 \\
\hline H60_V & 1.01 & 2.71 & 0.73 & 1.75 & 1.25 & 1.20 \\
\hline S4 [2] & 1.17 & 0.46 & 0.94 & 2.26 & 1.05 & 1.61 \\
\hline S9 [2] & 1.05 & 2.15 & 0.84 & 2.02 & 1.25 & 1.45 \\
\hline M1 [3] & 1.01 & 0.62 & 2.06 & 4.94 & 0.40 & 0.94 \\
\hline M2 [3] & 0.98 & 1.16 & 2.01 & 4.92 & 0.40 & 0.92 \\
\hline
\end{tabular}




\subsubsection{Deformation}

The normalized peak shear stress versus ultimate drift ratio $\left(d_{u}\right)$ of all test specimens is presented in Fig. 5. Previous research indicates that the wall deformation capacity increase when the horizontal web reinforcement is used (Maier [2] and Greifenhagen and Lestuzzi [3]). It appears that the test results of specimen $\mathrm{H} 60$ and H60_V with shear stress close to $10 A_{c v} \sqrt{f_{c}^{\prime}}$ (psi) support the previous findings. Despite of using different test setups and reinforcement detailing (with/without special boundary element), the trend in Fig. 5 shows that specimen deformation capacity tends to increase as the specimen normalized shear stress decreases.

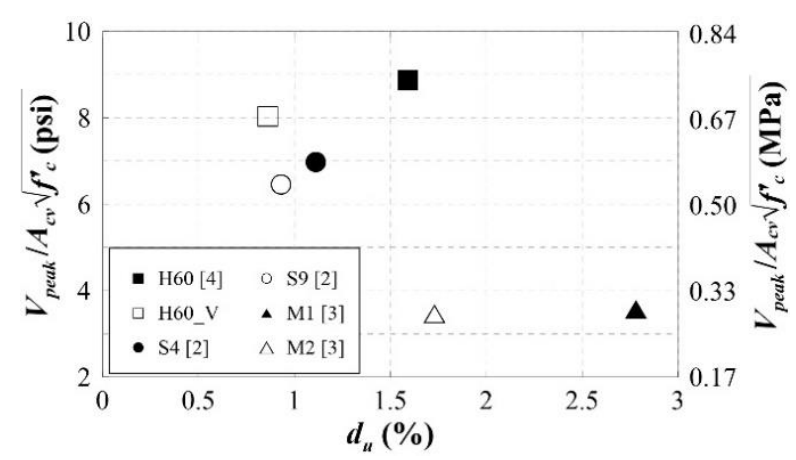

Fig. 5. Normalized Shear Stress vs drift

\section{Conclusion}

This study extends the work from Maier [2], Greifenhagen and Lestuzzi [3] and Cheng et al. [4] to evaluate effects of uniformly distributed horizontal web reinforcement on cyclic behavior of RC squat walls. Among the six specimens (three pairs) discussed in this study, one specimen was tested by the authors. Shear stress demand for each specimen pair is $3.5 \sqrt{f_{c}^{\prime}}$ (psi), $6.0 \sqrt{f_{c}}(\mathrm{psi})$, and $8.0 \sqrt{f_{c}^{\prime}}$ (psi), respectively. Based on limite test results, the following conclusions are drawn:

1) Regardless of the presence of unifomly distributed web reinforcement, the peak strength of each specimen pair is similar and can be satisfactorily estimated by the nominal flexural strength.

2) Specimen deformation capacity, however, increases when the horizontal web reinforcement is used.

\section{References}

1. Moehle, J. P., Ghodsi, T., Hooper, J. D., Fields, D. C., and Gedhada, R., Seismic Design of Cast-in-Place Concrete Special Structural Walls and Coupling Beams: A Guide for Practicing Engineers, National Institute of Standards and Technology, 37. (2011)

2. Maier, J., Shear Wall Tests., Preliminary Proceedings, International Workshop on Concrete Shear in
Earthquake, University of Houston, Texas, 85-94. (1992)

3. Greifenhagen, C., and Lestuzzi, P., Static Cyclic Test On Lightly Reinforced Concrete Shear Wall. Engineering Structures, 27, Jun., 1703-1712. (2005)

4. Cheng, M-. Y., Hung, S-. H., Lequesne, R. D., Lepage, A., Earthquake-Resistant Squat Walls Reinforced with High Strength Steel, ACI Structural Journal, 113, No.5, Sep.- Oct., 1065-1076. (2016)

5. ACI Committee 318, Building Code Requirements for Structural Concrete and Commentary (ACI 318-14), American Concrete Institute, Farmington Hills, Michigan,519 (2014)

6. Wood, S. L., Shear Strength of Low-Rise Reinforced Concrete Walls, ACI Structural Journal, 87, No. 1, Jan.-Feb., 99-107. (1990)

7. Hwang, S. -J., and Lee, H. -J., Strength Prediction for Discontinuity Regions by Softened Strut-and-Tie Model, Journal of Structural Engineering, ASCE, 128, No. 12, Dec., 1519-1526. (2002)

8. Gulec, C. K. and Whittaker, A. S., Empirical Equations for Peak Shear Strength of Low Aspect Ratio Reinforced Concrete Walls, ACI Structural Journal, 108, No. 1, Jan.-Feb., 80-89. (2011) 